\begin{tabular}{|l|r|r|}
\hline \multicolumn{2}{|c|}{ DJS Vol. 36 (2013) 14-19 } \\
\hline $\mathbf{1 9 6 9}$ & $\begin{array}{c}\text { Delta Journal of Science } \\
\text { Available online at } \\
\text { https://djs.journals.ekb.eg/ }\end{array}$ & \\
\hline Research Article & BOTANY \\
\hline
\end{tabular}

\title{
Investigation in the roots compositions of the Pimpinella boissieri M. Heroe grown wild in Kurdistan - Iraq using GC and LC-MS
}

\section{DARA M. JAMIL1, ALI ASKARI1, JONATHAN E. BROWN1, NAZLIN K. HOWELL1.}

1 Division of Nutritional Sciences, Faculty of Health and Medical Sciences, University of Surrey, Guildford, UK.

2 Division of Chemical Sciences, Faculty of Health and Medical Sciences, University of Surrey, Guildford, UK.

3 Food Science Department, Faculty of Agricultural Sciences, University of Sulaimani, KRG, Iraq.

E-mail: daramjamil@yahoo.co.uk.

\begin{abstract}
Many plant root extracts are known for their potential medicinal uses on living systems due to one or more of their active compounds. In this study, the root's composition of a rare species of pimpinella "Pimpinella boisseiri" grown in wild in Kurdistan - Iraq was investigated after being freeze dried, ground, extracted and purified. The purified ethanolic extract was analysed by LCMS and two chlorogenic acids were identified including 3, 4, 5, - Caffeoylquinic acid, 3,4 DicaffeolyQuinic Acid and 3, 5-Feruloyl Quinic Acid. Hydro-distillation extract of the ground roots resulted in obtaining azulene $(0.5 \%)$. This characterization of pimpinella root extracts revealed the presence of the chlorogenic acids and Azulene. On SEM analysis with built-in XRay analysis for the endosperm and the outer coat of the roots, the former showed to contain $\mathrm{Mg}, \mathrm{P}, \mathrm{S}$, and $\mathrm{K}$, whereas the outer coat found to contain calcium and to a lesser extend iron, beside the elements found in the endosperm.
\end{abstract}

KEYWORDS: Pimpinella boisseiri, chlorogenicn acids, Caffeoylquinic acid, Feruloyl quinciacid, Azulene, LC-MS, SEM, X-Ray analysis.

\section{INTRODUCTION}

Pimpinella, also called Umbelliferae, is a member of Apiaceae family. Pimpinella grows in wild in different parts of Medetrainian and Asian regions including Iraq, Syria, Turkey, Greece, Iran, Pakistan, Afghanistan (Askari et al., 2005; Mozaffarian,1996). The genus Pimpinella, encompasses 150 species distributed in the northern hemisphere (Heywood, 1971), most of which are annuals and perennials. The genus is prominent in medicinal and pharmaceutical uses, among which P. anisum being the most well known (Duke, 2006; Tabanca et al., 2005). The major chemical constituents of pimpinella were identified as anethol (Chandler and Hawkes, 1984; Fujita and Nagasawa, 1960), estragole (Zargari, 1989), psedoisoeugenol (Reichling et al., 1995), methylchavicol and anisaldehide (Wagner et al., 1984), coumarins, scopoletin, umbelliferone, estrols (Burkhardt, Reichling, Matin and Becker, 1986), terpene hydrocarbons (Karting, Moeckel and Mauns, 1975), polyenes and polyacetylene (Schulte, Rucker and Backe, 1970). Pimpinella oil extracts are known to be rich in phenylpropanoid derivatives of which psedoisoeugenol are distinctive to pimpinella (Kubecza, et al., 1997).

Although phenylpropanoids was identified as the characteristic compound in Pimpinella oils (Kubeczka et al., 1997), however, a number of other C12 sesquiterpenes such as geijerene and azulene that present in considerable amount were also reported, further concluding that from a chemotaxonomic stand point, $\mathrm{C} 12$ sesquiterpenes and phenylpropanoids are characteristic to the genus Pimpinella

and are phytochemical markers for this genus that separates them from all the other Apiaceae investigated thus far. (Tabanca et al. (2005)

Many members of this family are cultivated for various purposes. The plant structure includes a tap root, which can be large enough to be useful in food, as with parsnips (Pastinaca sativa), carrots (Daucus carota), and Hamburg parsley (Petroselinum crispum). Many plants of this group are also adapted to conditions that encourage heavy concentrations of essential oils, and as a result some are flavourful aromatic 
herbs. Examples are parsley (Petroselinum crispum), coriander (Coriandrum sativum), and dill (Anethum graveolens). The plentiful seeds of the umbers, likewise, are sometimes used in cuisine, as with, coriander (Coriandrum sativum), fennel (Foeniculum vulgare), cumin (Cuminum cyminum), and caraway (Carum carvi).

In the Iraqi flora, 15 species and four varieties of pimpinella were presented including (Pimpinella Anthriscoides BOISS, $P$. Barbata (bd.) BOISS. P. Barchyclada RESH. Et RIEDL, P. Corymbosa BOISS, P. Cretica POIR. P. Eriocarpos SOLAND Var. brevihirtum TOWNS, P. Kotschyana BOISS., P. Kurdica RECH. el RIEDL., P. Nephrophylla RECH. et RIEDL, $P$. Oliveriodes BOISS. et HAUSSRN., P. Olivieri BOISS., P. Perigrina L. Syn D. affinis Ledet. P. Puberula (DC.) BOISS., P. Tragium VILL., Var. pseudo-tragium (dc.) BOISS.Var. tragium, P. Zagrosica BOISS. et HASSKN. ). Interestingly the species and variety of $P$. Boisser var Hiroi (Fig.1) was not mentioned in the list.

\subsection{Pimpinella boissieri M. Hiroe}

P. boissieri is a tuberous plant with basal leaves 1-2 pinnate and basal leaflets petiolulate. The leaves are up to $20 \mathrm{~mm}$ long, leaflets lobed and coarsely toothed and almost glabrous, glaucescent. The flowering stem is up to $100 \mathrm{~cm}$ tall and is much divaricated. There are few umbles with only 3-4 rays, with no bracts or bracteols. The flowers are very small up to 1 $\mathrm{mm}$ across. Sepals are not seen, petals are yellowish green white strigose. The ovary is covered with strigose white hairs and the Stylopodium is orange with two short styles. The above description is for the species collected from mountains of Kurdistan that was identified by the Royal Botanic Gardens Kew-London - UK.

The fresh roots of this species are chewed and eaten by the local people for their calming and aphrodisiac effects. Since there is almost no information on this particular species, we may be the first to examine this species for its chemical composition. Based on the above, the roots of Pimpinella grown in the wild, were collected from Qaradakh mountains Sulaimai for investigation.
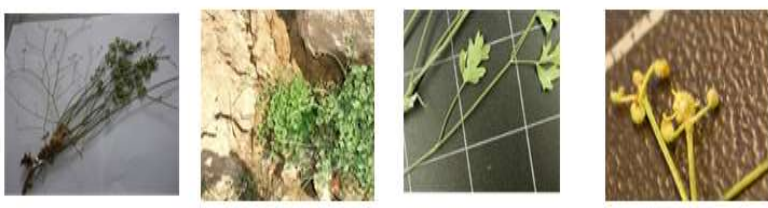

a.Wholedriedplant Fig.1.Pimpinellaboisseiri b. leaves. c. flowers

\section{Materials and Methods}

Materials: pimpinella whole plant (roots, leaves and flowers), Heto Lyolab 3000 freeze drier, Grinder, Soxtec Avanti 2055Sweden - FOSS, LC-MS with X-caliber software, Clavenger apparatus, Scanning Electronic Microscope (Hitachi S 3200SEM 3500) with build-in X-Ray, zinc acetate, Acetic Acid, Potassium ferro cyanide.

\subsection{LC-MS analysis:}

2.1. 1. The roots preparation: The first course of action was to clean the roots of Pimpinella from dried mud and debris with a brush followed by a cold wash of the roots with stream of tap water. The roots were then freeze-dried on $-55^{\circ} \mathrm{C}$ for 24 hours using Heto Lyolab 3000 freeze drier. The dried roots then crushed with pestle and mortar, followed by a thorough grinding, using professional range morphy richards ${ }^{\mathrm{TM}}$ blender and mill.

2.1.2. Roots Extraction: The ground roots were solvent extracted (Methanol $80 \%+20 \%$ MQ water) using a fully automated soxhlet analyser (Soxtec Avanti 2055 - Sweden FOSS). The extraction process was run for 1 hour on $130^{\circ} \mathrm{C}$ and 10 min rinsing time. The extract was collected in a $250 \mathrm{ml}$ volumetric flask, and the solvent was separated using rotary evaporator. The extract was centrifuged (2000rpm, for 20 minutes) and the filtrate was collected in a clean beaker.

2.1.3. Extract purification: The extract was cleaned up from the proteins and carbohydrates residues by adding $1 \mathrm{ml}$ of each solutions Carrez A (21.9g zincAcetate in water with $3 \mathrm{ml}$ Acetic Acid), and Carrez B(10.6 Potassium ferro cyanide in water) to $20 \mathrm{ml}$ extract in a universal disposable tubes with screwed caps. The tubes then vortexed for $1 \mathrm{~min}$ and let stand for 30 seconds followed by centrifugation ( $2000 \mathrm{rpm}$, for 10 minutes). The clean pure filtrate was decanted, collected in a dark glass bottle and kept in the fridge on $4^{\circ} \mathrm{C}$ for further analysis.

2.1.4. LC-MS analysis: One $\mathrm{ml}$ of the pure extract was filtered with Wattman 0.45 micrometer using a disposable syringe in to a vial, which was placed in the LC-MS auto sampler compartment for run. The solvent system were solvent A: $(99.5 \%$ acetonitrile $+0.5 \%$ Acetic acid), and solvent B: $(2 \%$ Acetonitrile, $0.5 \%$ Acetic acid and made up with Milli Q water). The LC-MS condition was as follow: The solvent gradient was from $0-90$ minutes (A: $96 \%+$ B: $4.0 \%$ ), 90-95minutes ( A: $67 \%+\mathrm{B}: 33 \%$ ), $95-105$ minutes ( A: $0 \%+$ B: $100 \%$ ), 105-110 minutes (A: $96 \%+$ B: $4 \%$ ). The column used $(150 \mathrm{~mm} \times 3 \mathrm{~mm}$, luna 5micron - phenyl-hexyl packing, phenomenex), the UV detector was set at wavelengths of A:280, B: 324 and C: $450 \mathrm{~nm}$.

20 microliters of the samples and Blank (Methanol) were automatically injected, at a flow rate $0.3 \mathrm{ml} / \mathrm{min}$ and pressure of $0-6000 \mathrm{psi}$. The time run was set for 110 minutes to elute all the phenolic compounds that might be present in the root sample, and the results mass/charge ratio spectrum for the ionised compounds were obtained. The LC-MS technique was controlled by Xcalibour software and the run was on negative ionization mode.

2.2. Hydro distillation: A known amount of ground roots was weighed and transferred in to a $1 \mathrm{~L}$ round bottom flask, mixed with $500 \mathrm{~mL}$ MilliQ water. The reflux was run on $80{ }^{\circ} \mathrm{C}$ for $3 \mathrm{H}$, and the volatile compounds were collected in the graduated tube of the Clavenger. Following cooling down the system, the dark navy blue oil was dried with anhydrous sodium sulphate and transferred in to a vial for GC-MS analysis.

\section{SEM and X-Ray analysis:}

\subsection{Sample preparation:}

3.1.a. Carbon coating: A clean part of the root was selected and various cross and long sections were made out of it using sculptor blades. The root sections were placed and stuck on the studs with aids of two sided adhesive buttons. The samples were then placed on the Carousel (a round disc) for carbon coating machine, where the carbon vapor coats the samples under the action of a highly electric current in a chamber that was vacuumed in advance for 25 minutes. Since the carbon vaporization did not go satisfactorily, so we thought of a second coating with chromium. 
3.1.b. Chromium coating: In this process Argon gas was used to make plasma on the target, which is a chromium disc, under which action the atoms of chromium sputter and make a deposit on the samples. The operating chamber has to be vacuumed till the screen shows high vacuum when the turbo speed reaches $100 \%$. Under these circumstances the first oxidised chromium particles will fall on the cover disc, the process continues till a glow of pink-violet light starts sputter the samples for about 3 minutes resulting a layer of $\approx 10 \mathrm{~nm}$ chromium on the samples.

3.1.c. Carbon Daging: Carbon liquid was added to all the samples on the plate prior taken them for analysis, thus the samples remained secure on the studs and it also helped better analytical resolution. The samples were then taken to SEM X-Ray analysis. The used model was: Hitachi S 3200SEM, 3500 maximum magnification.

\subsection{Analysis:}

Following the insertion of the samples into the SEM chamber, the chamber/Column was vacuumed. The tungsten plate on the top of the column was heated up, pouring electrons on the surface of the samples, by which the secondary electrons (from the samples) were reflected, scanned, amplified and the image captured. The sample was then analysed for Energy Dispersive X-Ray analysis to identify its elemental content

\section{RESULTS And Discussion}

This study was carried out to investigate the composition of the roots of a pimpinella species which was identified as Pimpinella boisseiri at Royal Botanic Gardens - KewLondon. First it is worth to say that this is the first report on Pimpinella boissieri species as there was no any electronically available information on this pimpinella species. The roots were cleaned from all the soil residues by thorough cleaning with brush and heavy stream of tap water followed by freeze drying. The roots were finely ground and homogenized in order to obtain the maximum ingredients possible.

The ground roots were extracted in a Clavengar and the reflux were running for 3 hours after which indigo blue oil was obtained. In deed in the first instant it was thought the blue color was due to the contamination of the system, however, after several successful trial the same results were obtained. The average amount of the blue oil was measured and found as $0.5 \%$ (Table. 1 ).

The blue oil was confirmed as azulene (Fig.1) after its analysis by GC-MS with inbuilt library software. In deed azulene is not a natural compound of the root but it was an artifact formed during hydrodistillation. Azulene is an aromatic organic compound made of seven carbon ring fused with five carbons which is widely used in cosmetics.

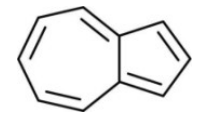

Fig.1 Azulene structure

Table 1. Average content of Azulene in freeze dried pimpinella boisseiri roots using clavenger.

\begin{tabular}{|c|c|c|}
\hline $\begin{array}{l}\text { Ground } \\
\text { samples g. }\end{array}$ & root & $\%$ a Azulene \\
\hline 50 & & 0.045 \\
\hline
\end{tabular}

\begin{tabular}{ll}
\hline 50 & 0.50 \\
50 & 0.50 \\
Average & 0.50 \\
\hline
\end{tabular}

In soxhlet extraction, the oil of finely ground roots of pimpinella roots were collected from the methanolic extract using rotary evaporator. The collected oil was purified from carbohydrates and protein residues with Carez (A and B) solution, in order to maximize the oil purity for Chromatographic analysis.

The oil was analysed by LC-MS using X - caliber software and the ratio of mass to ions $(\mathrm{m} / \mathrm{z})$ of the compounds were measured including close calculation to their MS1, MS2 and MS3 of the compounds fragments. The major chlorogenic acids identified were Caffeoylquinic acid (3, 4, 5-CQA m/z = 352.5 - 353.5) of peak developed at Rt $17 \mathrm{~min}$. and Feruloyltartaric acid $(\mathrm{m} / \mathrm{z}=324.5-325.5)$ of peak developed at Rt 39 min (Fig.2). However, other iso isochlorogenic acids (Josef et al., 1965) including dicaffeoylquinic acid (3,4 and 3,5 diCQA $\mathrm{m} / \mathrm{z}=514.5-515.5)$ and Caffeoylcoumaroylquinic acid (CpCoQA $\mathrm{m} / \mathrm{z}=509)$, though present in lesser amount were also identified. Chlorogenic acids are family of esters of hydroxycinnamic acids (caffeic acids, ferulic acids and $\mathrm{p}$ comaric acids with quinic acids (Clifford et al. 2003) Chlorogenic acid is an important intermediate in lignin biosynthesis, beside being a well known antioxidant, it also helps slowing the glucose release into a bloodstream after a meal (Johnston et al. 2003).

Following the preparation of the pallets of the ground roots, three samples of each of the endosperm and the outer coat of the ground roots were scanned with electron microscope with $\mathrm{X}$-Ray inbuilt and were analysed for their elemental contents Table 2 ( $a$ and $b$ ).

The X-Ray results revealed that the outer coats contain higher amount of the elements ( $\mathrm{Mg}, \mathrm{P}, \mathrm{S}$ and $\mathrm{K}$ ) comparing to the endospermic contents. Of particular interest the outer coat found to be rich in calcium and to lesser extend in iron whereas there were no trace of these elements in the endosperm, but Selenium found in none of them. Conclusively, it is worth to examine the identified chlorogenic acids found in pimpinella boissieir roots for their antioxidant activities as well as for their in vivo biological impacts especially on slowing sugar absorption

\section{REFERENCE}

Heywood, V.H., 1971. The Biology and Chemistry of the Apiaceae. Linnean Society of London, London, p. 232.

Duke's Phytochemical and Ethnobotanical Databases, 2006. Ethnobotanical uses of Pimpinella. Available from: http://www.ars-grin.gov.

Tabanca, N., Bedir, E., Ferreira, D., Slade, D., Wedge, D.E., Jacob, M.R., Khan, S.I., Kirimer, N., Baser, K., Khan, I.A., 2005a. Bioactive constituents from Turkish Pimpinella species. Chemistry and Biodiversity, 2, 221-232.

Fujita, M., \& Nagasawa, N. (1960). Analysis of anethole containing drugs I.R. spectrophotometry. Chemical Abstracts, 54,20092 .

Zargari, A. (1989). Medicinal Plants (Vol. 2). Tehran: Tehran University. 
Reichling, J., Kemmerer, B., \& Sauer, G. H. (1995). Biyosynthesis of pseudoisoeugenols in tissue cultures of Pimpinella anisum. Pharmacy World and Science, 28, 113119.

Wagner, H., Bladt, S., \& Zgainski, F. M. (1984). Plant drug analysis. New York: Springer-Verlag.

Burkhardt, G., Reichling, J., Martin, R., \& Becker, H. (1986). Terpene hydrocarbons in Pimpinella anisum. Pharmacy Weekly Science, 8,190-193.

Kartnig, T., Moeckel, H., \& Mauns, B. (1975). Occurence of coumarins and sterols in tissue cultures of roots of Anethum graveolens and Pimpinella anisum. Planta Medica, 27, 1-4.

Schulte, K. E., Rucker, G., \& Backe, W. (1970). Polyacetylenes from Pimpinella species. Archive Der Pharmazie, 303, 912-919.

Kubeczka, K. H., \& Ullmann, I. (1980). Occurence of 1,5dimethylcyclodeca-1,5,7-triene (pregeijerene) in Pimpinella species and chemosystematic implications. Biochemical Systematics and Ecology, 8, 39-41.

Clifford, M. N.; Johnston, K. L.; Knigh, S.; Kuhnert, N. (2003). "Hierarchical Scheme for LC-MS ${ }^{\mathrm{n}}$ Identification of Chlorogenic Acids". Journal of Agriculture and Food chemistry 51 (10): 2900-2911.

Johnston, K. L.; Clifford, M.N.; Morgan, L.M. (2003). "Coffee acutely modifies gastrointestinal hormone secretion and glucose tolerance in humans: glycemic effects of chlorogenic acid and caffeine". American Journal of Clinical Nutrition (American Journal of Clinical Nutrition) 79 (4): 728-733.

Joseph Corse, R.E. Lundin and A.C. Waiss (1965). Identification of several components of isochlorogenic acid. Jr. Phytochemistry, Vol. 4 ( 3):527-529.

Mozaffarian, V., 1996. A Dictionary of Iranian Plant Names. Farhang Moaser, Tehran, Iran, p. 412.

Askari, F., Sefidkon, F., Mozafarian, V., 2005. Essential oil composition of Pimpinella aurea S.C. from Iran. Flavour and Fragrance Journal 20, 115-117.

K.H. Kubeczka, I. Bohn, W. Schultze, Z. Naturforsch. C 44 (1989) 177

A. Velasco-Negueruela, M.J. Perez-Alonso, P.L. Perez de Paz, J. Pala-Paul, J. Sanz, J. Chromatogr. A 1011 (2003) 241.

K.H. Kubeczka, in: K.H.C. Baser, N. Kirimer (Eds.), Proceedings of the 28th International Symposium on Essential Oils, Eskisehir, Turkey, 1-3 September, 1997, p. 35.
N.Tabanca a, B. Demirci b, N. Kirimer b, K. Husnu Can Baser b, $\square$, E. Bedir c, I A. Khand,e, D. E. Wedge (Gas chromatographic-mass spectrometric analysis of essential oils from Pimpinella aurea, Pimpinella corymbosa, Pimpinella peregrine and Pimpinella puberula gathered from Eastern and Southern Turkey). Journal of Chromatography A, 1097 (2005) 192-198. 


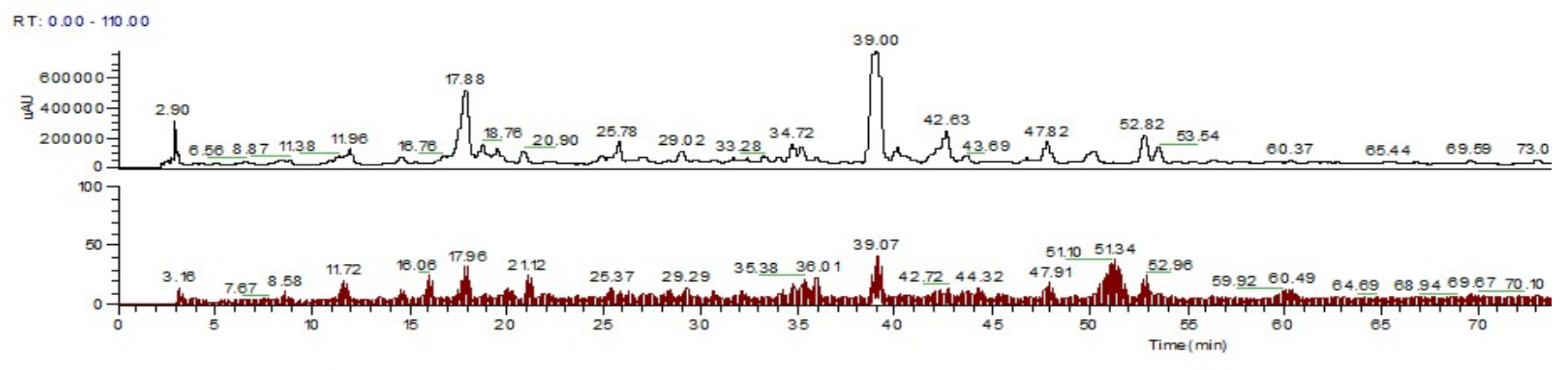

Pure extract - pimpinella-E thol_01\#946 RT: 17.96 AV: 1 NL: $9.94 E 6$

T: - cESIF ull ms [ 120.00-1000.00]

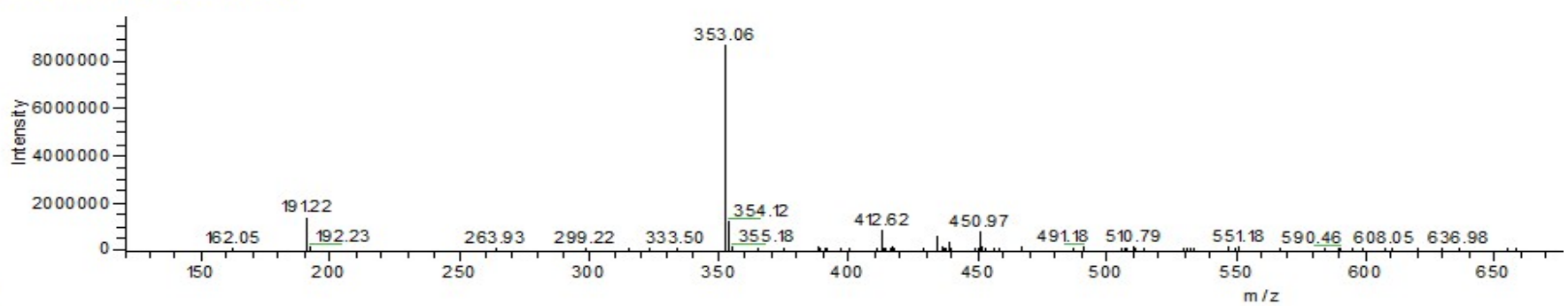

Fig.2. The LC-MS chromatogram and mass spectrum of a. Caffeoyl quinic acids and $b$. Feruloyl-tartaric acid

Table 2. a. Pimpinella roots - ground endosperm X-Ray qualitative elemental contents.

\begin{tabular}{rrrrrrrrr}
\hline Elements & \multicolumn{3}{c}{ Sample 1 } & \multicolumn{3}{c}{ Sample 2 } & \multicolumn{3}{r}{ Sample 3 } & Average \\
& Weight & Atomic & Weight & Atomic & Weight & Atomic & Weight & $\begin{array}{r}\text { Atomic } \\
\%\end{array}$ \\
& $\%$ & $\%$ & $\%$ & $\%$ & $\%$ & $\%$ & $\%$ & $\%$ \\
\hline CK & 80.96 & 85.96 & 80.77 & 85.29 & 81.40 & 85.78 & 81.04 & 85.67 \\
OK & 15.87 & 12.65 & 17.99 & 14.26 & 17.46 & 13.81 & 17.10 & 13.57 \\
Mg K & 0.09 & 0.05 & 0.16 & 0.08 & 0.15 & 0.08 & 0.13 & 0.07 \\
Al K & 0.00 & 0.00 & 0.00 & 0.00 & 0.00 & 0.00 & 0.00 & 0.00 \\
Si K & 0.00 & 0.00 & 0.07 & 0.03 & 0.00 & 0.00 & 0.02 & 0.01 \\
P K & 0.15 & 0.06 & 0.12 & 0.05 & 0.17 & 0.07 & 0.15 & 0.06 \\
S K & 0.09 & 0.04 & 0.08 & 0.03 & 0.00 & 0.00 & 0.06 & 0.02 \\
Cl K & 0.00 & 0.00 & 0.00 & 0.00 & 0.00 & 0.00 & 0.00 & 0.00 \\
K K & 0.43 & 0.14 & 0.52 & 0.17 & 0.52 & 0.17 & 0.49 & 0.16 \\
Ca K & 0.26 & 0.08 & 0.30 & 0.10 & 0.31 & 0.10 & 0.29 & 0.09 \\
Fe K & 0.00 & 0.00 & 0.00 & 0.00 & 0.00 & 0.00 & 0.00 & 0.00 \\
Se L & 0.00 & 0.00 & 0.00 & 0.00 & 0.00 & 0.00 & 0.00 & 0.00 \\
Total & 100.00 & & 100.00 & & 100 & & & \\
\hline
\end{tabular}


Table 2. b. Pimpinella roots - outer coat $X$-Ray qualitative elemental contents.

\begin{tabular}{|c|c|c|c|c|c|c|c|c|}
\hline \multirow[t]{3}{*}{ Elements } & \multicolumn{3}{|c|}{ Sample 1} & \multirow{3}{*}{$\begin{array}{l}\text { Sample } 2 \\
\text { Atomic } \%\end{array}$} & \multicolumn{3}{|c|}{ Sample 3} & \multirow{3}{*}{$\begin{array}{r}\text { Average } \\
\text { Atomic } \\
\%\end{array}$} \\
\hline & Weight & Atomic $\%$ & Weight & & Weight $\%$ & Atomic & Weight & \\
\hline & $\%$ & & $\%$ & & & $\%$ & $\%$ & \\
\hline CK & 81.05 & 86.01 & 81.85 & 86.77 & 81.24 & 86.34 & 81.30 & 84.5 \\
\hline $\mathrm{OK}$ & 16.38 & 13.05 & 15.32 & 12.19 & 15.35 & 12.25 & 12.5 & 13.3 \\
\hline $\mathrm{Mg} \mathrm{K}$ & 0.24 & 0.13 & 0.28 & 0.15 & 0.19 & 0.10 & 0.23 & 0.13 \\
\hline $\mathrm{Al} \mathrm{K}$ & 0.09 & 0.04 & 0.10 & 0.05 & 0.57 & 0.24 & 0.25 & 0.11 \\
\hline Si K & 0.34 & 0.16 & 0.34 & 0.15 & 0.29 & 0.13 & 0.32 & 0.15 \\
\hline P K & 0.13 & 0.05 & 0.14 & 0.06 & & & 0.13 & 0.05 \\
\hline S K & 0.09 & 0.04 & 0.11 & 0.04 & & & 0.10 & 0.04 \\
\hline $\mathrm{Cl} \mathrm{K}$ & & & 0.12 & 0.04 & & & 0.12 & 0.04 \\
\hline K K & 0.69 & 0.22 & 0.81 & 0.26 & 0.67 & 0.22 & 0.72 & 0.23 \\
\hline $\mathrm{Ca} \mathrm{K}$ & 0.77 & 0.25 & 0.77 & 0.24 & 0.69 & 0.22 & 0.74 & 0.24 \\
\hline $\mathrm{Fe} \mathrm{K}$ & 0.20 & 0.04 & 0.17 & 0.04 & 0.19 & 0.04 & 0.19 & 0.04 \\
\hline Se L & & & 0.00 & 0.00 & 0.00 & 0.00 & 0.00 & 0.00 \\
\hline Total & 100.00 & & 100.00 & & 100 & & & \\
\hline
\end{tabular}

